Check for updates

Cite this: J. Mater. Chem. A, 2021, 9 , 8386

Received 17th November 2020 Accepted 28th February 2021

DOI: 10.1039/d0ta11229a

rsc.li/materials-a

\title{
Guest size limitation in metal-organic framework crystal-glass composites $\uparrow$
}

\author{
Christopher W. Ashling, (D) a Lauren K. Macreadie, (D) ${ }^{b}$ Thomas J. F. Southern, (D) a

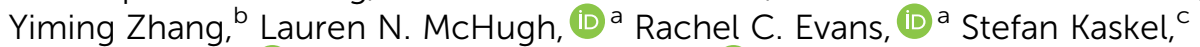 \\ Shane G. Telfer (iD ${ }^{* b}$ and Thomas D. Bennett (D)*a
}

\begin{abstract}
Metal-organic framework crystal-glass composites (MOF CGCs) have previously been formed by embedding crystalline MIL-53(Al) within a ZIF-62 glass ( $a_{g}$ ZIF-62) matrix. Here we highlight thermal stability considerations in the formation of MOF CGCs, and subsequently report the synthesis of two novel MOF CGCs, by incorporating MIL-118 and UL-MOF-1 within $a_{\mathrm{g}}$ ZIF-62. These new materials, alongside the prototypical MOF CGC, formed using MIL-53(Al), were studied using scanning electron microscopy, powder X-ray diffraction, and gas sorption techniques. The gas uptake in composites formed from MIL-118C and UL-MOF-1 is largely dominated by the $a_{\mathrm{g}}$ ZIF-62 matrix, suggesting that to improve the porosity of the MOF CGC, the matrix porosity must be improved, or a percolation threshold must be overcome.
\end{abstract}

\section{Introduction}

Metal-organic frameworks (MOFs) are hybrid materials containing inorganic nodes, or clusters, linked together by organic units in continuous networks. ${ }^{1}$ These hybrid materials can be constructed using numerous combinations of metal ionstypically d-block elements-and polydentate ligands. Consequently, over 99000 unique MOFs have been reported in the literature, many of which possess exceptionally high surface areas. $^{2}$ The hypothetical potential of such surface areas in MOFs has been predicted to reach $\sim 14600 \mathrm{~m}^{2} \mathrm{~g}^{-1,3,4}$ though currently, the largest reported Brunauer-Emmett-Teller (BET) surface area is $7839 \mathrm{~m}^{2} \mathrm{~g}^{-1}$. Accordingly, they are of interest for several applications, such as sensing, gas storage, and water harvesting. ${ }^{1,5-7}$

A wide range of stimuli-responsive behaviour is observed by MOFs as a result of their chemical and physical diversity. ${ }^{8}$ Some frameworks, such as UiO-66, are commonly referred to as 'rigid' and display little, or no, structural change upon application of (non-extreme) external stimuli. ${ }^{9}$ Others, however, undergo reversible structural transformations under relatively mild pressure or temperature changes; these are referred to as flexible MOFs. ${ }^{10}$ Perhaps the most commonly illustrated example of

${ }^{a}$ Department of Materials Science and Metallurgy, University of Cambridge, Cambridge, CB3 OFS, UK. E-mail: tdb35@cam.ac.uk

${ }^{b}$ MacDiarmid Institute for Advanced Materials and Nanotechnology, Institute of Fundamental Sciences, Massey University, Palmerston North, New Zealand ${ }^{c}$ Technische Universität Dresden, Bergstrasse 66, 01062 Dresden, Germany

$\dagger$ Electronic supplementary information (ESI) available: Powder X-ray diffraction, thermogravimetric analysis, scanning electron microscopy, and gas sorption isotherms. See DOI: 10.1039/d0ta11229a flexibility in MOFs is the phenomenon of "breathing". An example of this occurs in the $\mathrm{MOF} \mathrm{Al}_{2}(\mathrm{bdc})_{3}$ (bdc - benzene-1,4dicarboxylate, $\mathrm{C}_{8} \mathrm{H}_{4} \mathrm{O}_{4}{ }^{2-}$ )-referred to as MIL-53 from hereonwhich undergoes a solid-solid phase transition from a narrowpore phase at room temperature to a metastable large-pore phase upon desolvation at high temperature. ${ }^{11}$ The breathing effect in MIL-53 dynamically changes the pore volume and, by extension, alters the guest uptake capacity. Understanding such transitions is important for designing materials for molecular separations, catalysis, and gas storage since the interaction strength between host and guest is dependent upon pore size.

Reversible breathing behaviour represents just a small portion of the structural rearrangements exhibited by MOFs; further examples include recrystallisation, interpenetrated lattice movements and irreversible collapse upon solvent/guest removal. ${ }^{12}$ The most extensive of the observed rearrangements occur in a subset of MOFs known as zeolitic imidazolate frameworks (ZIFs), which contain an imidazolate-derived linker (Im, $\mathrm{C}_{3} \mathrm{H}_{3} \mathrm{~N}_{2}{ }^{-}$), and adopt network topologies similar to those of inorganic zeolites. Heating under ambient pressure results in several ZIF structures undergoing melting to highly viscous liquid phases. ${ }^{\mathbf{1 3}}$ These liquids then solidify upon cooling to form glasses in which tetrahedral $\mathrm{Zn}^{2+}$ ions are linked by imidazolate ligands in a continuous random network, analogous to that of amorphous silica.

The glass formed from ZIF-62, $\mathrm{Zn}(\operatorname{Im})_{1.75}(\mathrm{bIm})_{0.25}(\mathrm{bIm}$, benzimidazolate, $\mathrm{C}_{7} \mathrm{H}_{5} \mathrm{~N}_{2}{ }^{-}$) ${ }^{14}$ (melting temperature, $T_{\mathrm{m}}=437$ $\left.{ }^{\circ} \mathrm{C}\right),{ }^{\mathbf{1 5}}$ has been identified as a suitable host matrix to secure crystalline MIL-53 particles within a bulk MOF structure. Specifically, a physical mixture of ZIF-62 and MIL-53 was heated to $450{ }^{\circ} \mathrm{C}$ for $15 \mathrm{~min}$ to melt the ZIF-62 and allow sufficient 
liquid flow around the crystalline component before cooling to room temperature; the resultant material is referred to as a MOF crystal-glass composite (MOF CGC). Interestingly, within this MOF CGC, the large-pore phase of MIL-53 was stabilised at room temperature, inducing a significant increase in the amount of $\mathrm{CO}_{2}$ adsorbed when compared to the uptake by a combination of the parent materials. ${ }^{16}$ The loading capacity of MIL-53 within the ZIF-62 glass ( $a_{\mathrm{g}}$ ZIF-62) matrix was also investigated, showing that $60-70$ wt $\%$ MIL-53 could be encapsulated in the composite whilst retaining the MIL-53-lp state. As a result, a composite was fabricated with a $\mathrm{CO}_{2}$ capacity considerably greater than the phase-pure MIL-53 parent material. ${ }^{17}$

To date, the MOF CGC formed from MIL-53 and $a_{\mathrm{g} Z I F-62}$ is the first of only three known examples of this class of materials. ${ }^{16-18}$ The extension of this approach to other crystalline MOFs is dependent upon their structural integrity at the temperatures required for the fabrication of the MOF CGC (e.g. $\left.437{ }^{\circ} \mathrm{C}\right) .{ }^{15}$ This is further complicated by the lack of thermal stability data using standardised atmospheric conditions and heating rates, and furthermore by the lack of data on stability when held isothermally at elevated temperatures. ${ }^{19}$

In turn, the lack of additional MOF CGC chemistries limits any further conclusions on the gas sorption and separation behaviour of these materials, which is confined to $\mathrm{N}_{2}$ and $\mathrm{CO}_{2}$ adsorption on MIL-53 based samples only. Such considerations motivated us to provide further examples of MOF CGCs from different crystalline chemistries and architectures and evaluate their gas adsorption behaviour.

\section{Results and discussion}

Several MOF candidates for the crystalline filler were selected according to their reported thermogravimetric analyses (TGA) indicating the required stability to $450{ }^{\circ} \mathrm{C}$ (Table 1) and were synthesised using the published procedures (see Experimental, Fig. S1-10 $\dagger$ ). Each of the eight frameworks selected was analysed using TGA conducted at a standard heating rate of $10{ }^{\circ} \mathrm{C} \min ^{-1}$ under inert nitrogen $\left(\mathrm{N}_{2}\right)$, to confirm thermal stability (Fig. S11 $\dagger$ ). The onset of thermal decomposition, $T_{\mathrm{d}}$, below $450{ }^{\circ} \mathrm{C}$ was only observed for samples of DUT- 6 and DUT8. However, the $T_{\mathrm{d}} \mathrm{S}$ of these two materials were greater than the reported values due to the faster heating rate used in our evaluation compared to those employed in the literature. As mass loss had already begun to occur at $450{ }^{\circ} \mathrm{C}$, and given the need for isothermal heat treatment at this temperature for CGC fabrication, this precluded further study of these specific materials (Fig. S12†).

To provide a more accurate evaluation of thermal stability, the remaining MOFs were heated to $450{ }^{\circ} \mathrm{C}$ for $1 \mathrm{~min}$, under $\mathrm{N}_{2}$, and allowed to cool to room temperature in situ. Ambient temperature powder X-ray diffraction (PXRD) data were then recorded (Fig. S1-S10 $\dagger$ ). This relatively simple experiment highlighted the importance of performing thermal analysis of MOFs using an appropriate set of conditions, chosen according to the individual processing or application requirements. For example, Bragg peaks intensities in the PXRD pattern for MIL-
Table 1 Reported thermal stabilities of crystalline MOF component candidates $^{b}$

\begin{tabular}{|c|c|c|c|c|}
\hline MOF & Composition & $\begin{array}{l}\text { Decomposition } \\
\text { temperature, } \\
T_{\mathrm{d}}\left({ }^{\circ} \mathrm{C}\right)\end{array}$ & $\begin{array}{l}\text { Heating rate } \\
\left({ }^{\circ} \mathrm{C} \min ^{-1}\right)\end{array}$ & Ref. \\
\hline $\begin{array}{l}\text { CUmof- } \\
9\end{array}$ & $\begin{array}{l}\mathrm{Yb}_{2}(2,6- \\
\mathrm{ndc})_{3}\left(\mathrm{H}_{2} \mathrm{O}\right) \cdot\left(\mathrm{H}_{2} \mathrm{O}\right)_{2}\end{array}$ & $550^{a}$ & 5 & 20 \\
\hline DUT-6 & $\begin{array}{l}\mathrm{Zn}_{4} \mathrm{O}(2,6-\mathrm{ndc})(\mathrm{btb})_{4 /} \\
{ }_{3}(\mathrm{def})_{16}\left(\mathrm{H}_{2} \mathrm{O}\right)_{9 / 2}\end{array}$ & $\sim 400$ & 5 & 21 \\
\hline DUT-8 & $\mathrm{Ni}_{2}(2,6-\mathrm{ndc})_{2}(\mathrm{dabco})$ & $\sim 400$ & 5 & 22 \\
\hline MIL-68 & $\mathrm{V}(\mathrm{OH})(\mathrm{bdc})$ & $\sim 500$ & 10 & 23 \\
\hline $\begin{array}{l}\text { MIL- } \\
118\end{array}$ & $\mathrm{Al}_{2}(\mathrm{OH})_{2}\left(\mathrm{C}_{10} \mathrm{O}_{8} \mathrm{H}_{2}\right)$ & $\sim 450$ & 1 & 24 \\
\hline $\begin{array}{l}\text { MIL- } \\
120\end{array}$ & $\mathrm{Al}_{4}(\mathrm{OH})_{8}\left(\mathrm{C}_{10} \mathrm{O}_{8} \mathrm{H}_{2}\right)$ & $\sim 480$ & 1 & 25 \\
\hline $\begin{array}{l}\text { MIL- } \\
126(\mathrm{Sc})\end{array}$ & $\begin{array}{l}\mathrm{Sc}_{3} \mathrm{O}\left(\mathrm{H}_{2} \mathrm{O}\right)_{2}(\mathrm{bpdc})_{3} \mathrm{X}(\mathrm{X} \\
=\mathrm{OH} \text { or } \mathrm{Cl})\end{array}$ & $\sim 500$ & 10 & 26 \\
\hline $\begin{array}{l}\text { UL- } \\
\text { MOF-1 }\end{array}$ & $\mathrm{Li}_{2}(2,6-\mathrm{ndc})$ & $610^{a}$ & 10 & 27 \\
\hline
\end{tabular}

${ }^{a}$ Experiment performed under an inert atmosphere. ${ }^{b} 2,6$-ndc $=$ naphthalene-2,6-dicarboxylate, bdc = benzene-1,4-dicarboxylate, bpdc $=$ biphenyl-4,4'-dicarboxylate, btb $=$ benzene-1,3,5-tribenzoate, def $=$ $N, N$-diethylformamide, dabco $=1,4$-diazabicyclo[2.2.2] octane.

68 (Fig. S2†) were reduced to near negligible levels, alongside a significant reduction in intensities, or changes in the patterns, for MIL-120 and MIL-126(Sc) (Fig. S3 and S4 $\dagger$ ). This is consistent with the thermal analysis performed by Volkringer et al., confirming that the first step in decomposition for MIL-120 is due to ligand degradation. ${ }^{25}$ An unreported recrystallisation of CUmof-9 was also observed (Fig. S1†), though the hightemperature phase was not identified. MIL-68, MIL-120, MIL126, and CUmof-9 were, therefore, not studied further.

The PXRD patterns of the three remaining samples: MIL-118, UL-MOF-1, and MIL-53-np (Fig. 1a-d), displayed Bragg peaks in good agreement with their room temperature structures after heating to $450^{\circ} \mathrm{C}$ (Fig. S5-S10 ${ }^{\dagger}$ ). UL-MOF-1 has been reported to display exceptional thermal stability $\left(T_{\mathrm{d}}=610^{\circ} \mathrm{C}\right)$; the structure consists of alternating two-dimensional antifluorite type lithium oxide layers connected by 2,6-ndc struts (Fig. 1c). ${ }^{27}$ No flexible behaviour has been reported for this material. Conversely, MIL-118, $\mathrm{Al}_{2}(\mathrm{OH})_{2}\left(\mathrm{C}_{10} \mathrm{O}_{8} \mathrm{H}_{2}\right)\left(\mathrm{C}_{10} \mathrm{O}_{8} \mathrm{H}_{2}{ }^{4-}\right.$ - benzene1,2,4,5-tetracarboxylate), exhibits a water-driven reversible structural transition, analogous to that of MIL-53. ${ }^{24}$ MIL-118 is typically synthesised with excess ligand in the pores of the framework and is named MIL-118A (C2/c). Upon heating MIL$118 \mathrm{~A}$, this excess ligand is removed, resulting in the openpore framework, MIL-118B (Pbam), which is stable at high temperatures. Upon cooling, the framework adsorbs water to form the room temperature stable phase, MIL-118C (Pnam). The transition causes a shift from the rectangular 1-D tunnels in MIL-118B to lozenge-shaped channels, with water molecules occupying the pores in MIL-118C. Temperature-induced breathing is observed between the MIL-118C and MIL-118B phases (Fig. 1a and b).

MOF CGCs containing $50 \mathrm{wt} \%$ crystalline UL-MOF-1 and MIL-118 were synthesised using the method previously 

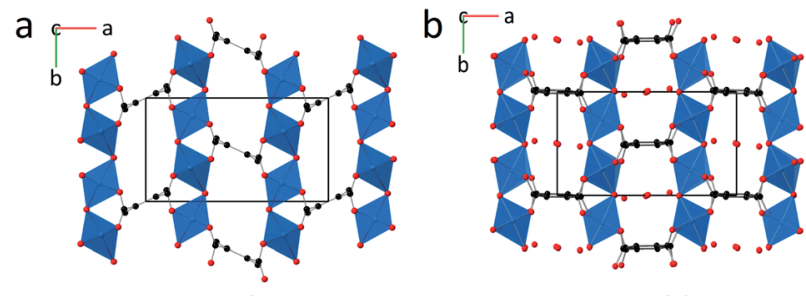

MIL-118B

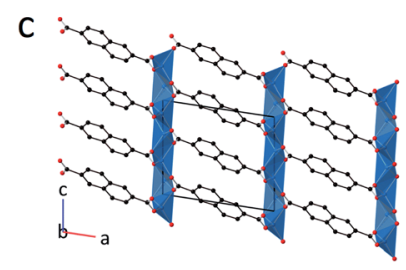

UL-MOF-1 d

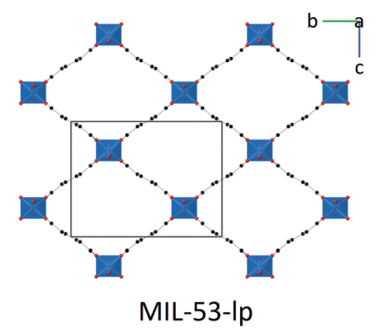

Fig. 1 Representations of (a) MIL-118B, (b) MIL-118C, (c) UL-MOF-1, (d) MIL-53-lp where; carbon - black, oxygen - red and M-O nodes replaced by blue polyhedra. Hydrogen atoms have been omitted for clarity. The unit cell is indicated by a black box with an overlay of crystallographic axes.

published in the literature for a CGC containing MIL-53. Briefly, the synthesis involved mixing the two crystalline components by ball-milling, pelletising the mixture, and heating to $450{ }^{\circ} \mathrm{C}$ under argon (for full procedure, see Experimental). These are referred to as (crystal) $)_{x}$ (glass) $)_{1-x}$ where $x=$ weight fraction of the crystalline material in the composite, consistent with prior nomenclature. The MOF CGC behaviour was compared to a sample of (MIL-53 $)_{0.25}\left(a_{\mathrm{g} Z I F-62}\right)_{0.75}$, synthesised according to previous methods. ${ }^{16}$

Ambient temperature PXRD data were recorded for the three MOF CGCs. As expected, Bragg peaks present in the crystalline sample of UL-MOF-1 were also present in (UL-MOF-1) $)_{0.5}\left(a_{\mathrm{g}} \mathrm{ZIF}-\right.$ 62) $)_{0.5}$. PXRD data for (MIL-53 $)_{0.25}\left(a_{\mathrm{g}} \mathrm{ZIF}-62\right)_{0.75}$ demonstrated the presence of the open-pore MIL-53 phase, per previous results. ${ }^{16,17}$ Interestingly, the PXRD data for (MIL-118) $)_{0.5}\left(a_{\mathrm{g}}\right.$ ZIF62) $)_{0.5}$ indicated little change in lattice parameters from the synthesised MIL-118 sample, which remained in the lowtemperature MIL-118C (Pnam) phase (Fig. 2 and Table S1†). This shows that, unlike the MIL-53 in (MIL-53) $)_{0.25}\left(a_{\mathrm{g}} \mathrm{ZIF}-62\right)_{0.75}$, the MIL-118 encapsulated within the glass does not retain the high-temperature MIL-118B (Pbam) phase (Fig. 1a).

In our previous work, we demonstrated that the ingress of water did not drive a transition from MIL-53-lp back to MIL-53$\mathrm{np}$ in a room temperature MOF CGC. ${ }^{16}$ It was, therefore, suggested that "the stabilisation of MIL-53-lp does not arise because it is excluded from entering the composite CGC material. Instead, we suggest that the polymeric phase is not soft enough to accommodate a large-scale change of the crystal phase structure, while the interfacial contact between the two phases is maintained". ${ }^{16}$

Here, it is perhaps the case that either (i) interfacial contact between MIL-118 and the glass is less than that of MIL-53 and the glass, and/or (ii) that the volume changes upon the

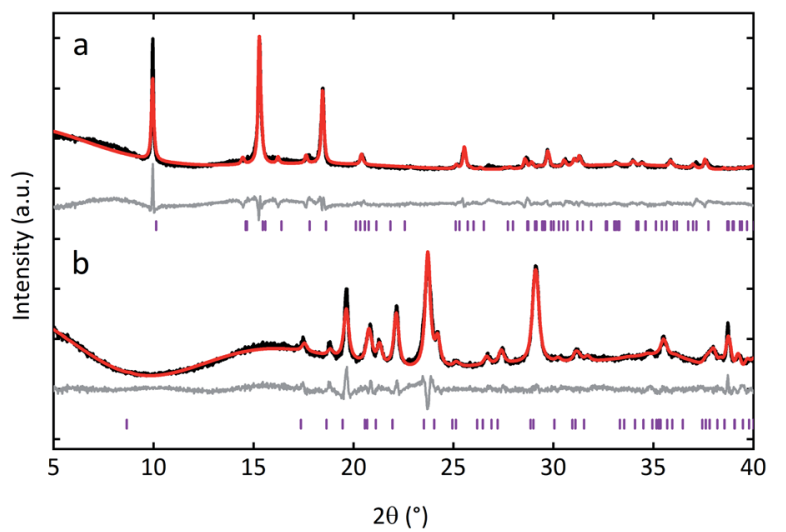

Fig. 2 PXRD data of (a) (MIL-118) $0.5\left(a_{\mathrm{g}} \text { ZIF-62) }\right)_{0.5}$, rwp: 11.152, and (b) (UL-MOF-1) $)_{0.5}\left(a_{\mathrm{g}}\right.$ ZIF-62) 0.5 , rwp: 7.677. Recorded data in black, Pawley refinements in red, difference patterns in grey, and $h k l$ indices in purple underneath the respective patterns.

transition from MIL-118B to MIL-118C can be accommodated by the glass phase.

Scanning electron microscopy (SEM) images of MIL-53-np, MIL-118, and UL-MOF-1 display micrometre-sized crystals (Fig. S13-S15†). Samples of MIL-118 and MIL-53 display reasonable size and shape uniformity in comparison to ULMOF-1, which comprises a range of morphologies from $10 \mu \mathrm{m}$ cubic structures to $200 \mu \mathrm{m}$ sheets (Fig. S15†). This occurs despite (i) X-ray diffraction phase purity which matches the reported crystallographic information, and (ii) a single thermal decomposition event at the reported temperature.

The MOF CGCs formed in each case demonstrated selfsupporting, contiguous, bulk morphologies. SEM performed upon deliberately fractured pieces of these materials did not contain distinguishable remnants of the respective parent crystalline phases at the surface of the composite (Fig. 3 and S16-S18†). Their self-supporting nature, coupled with the smooth surface of the MOF CGCs, provides evidence that the liquid ZIF-62 permeated through the pellet. However, a region of coarse material matching the morphology of MIL-118 was observed at a macroscale surface defect in the sample of (MIL118) $)_{0.5}\left(a_{\mathrm{g}} \mathrm{ZIF-62}\right)_{0.5}$ (Fig. S17†).

Prior work on MOF CGCs has investigated only the gas uptake behaviour of a series of (MIL-53 $)_{x}\left(a_{\mathrm{g}} \mathrm{ZIF}-62\right)_{1-x}$ CGCs with carbon dioxide $\left(\mathrm{CO}_{2}\right)$ and nitrogen $\left(\mathrm{N}_{2}\right) \cdot{ }^{16,17}$ A range of analyte gases was therefore employed here to investigate the factors underpinning gas uptake in MOF CGCs. Gas sorption isotherms were performed predominantly at $273 \mathrm{~K}$, with further experiments performed for some gases at $77 \mathrm{~K}$ and $293 \mathrm{~K}$. For full experimental methodology, see Experimental.

A sample of pure $a_{\mathrm{g} Z \mathrm{ZIF}-62}$ was prepared (see Experimental) and observed to exhibit porosity towards $\mathrm{H}_{2}\left(1.05 \mathrm{mmol} \mathrm{g}^{-1}\right.$ at $77 \mathrm{~K}$, and $0.18 \mathrm{mmol} \mathrm{g}^{-1}$ at $\left.273 \mathrm{~K}\right)$ and $\mathrm{CO}_{2}\left(0.95 \mathrm{mmol} \mathrm{g}^{-1}\right.$ at $273 \mathrm{~K}$ ) (Fig. 4 and S19†), both significantly lower than crystalline ZIF-62 which adsorbs $\sim 6.03 \mathrm{mmol} \mathrm{g}^{-1} \mathrm{H}_{2}$ at $77 \mathrm{~K}$ and $\sim 1.79 \mathrm{mmol} \mathrm{g}^{-1} \mathrm{CO}_{2}$ at $273 \mathrm{~K}^{28}$ These results are in accordance with previous studies which demonstrate porosity in ZIF-glass materials. ${ }^{29}$ 


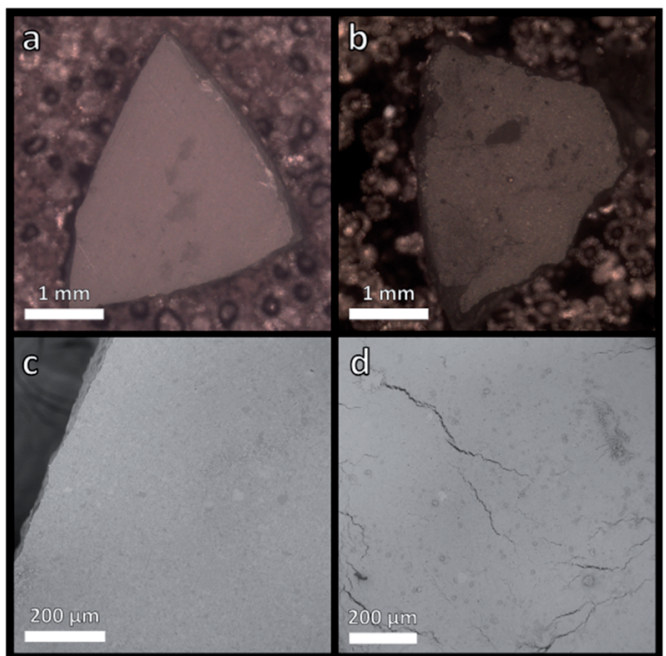

Fig. 3 Optical images of (a) (MIL-118) $)_{0.5}\left(a_{\mathrm{g}} Z \mathrm{IF}-62\right)_{0.5}$, and (b) (ULMOF-1 $)_{0.5}\left(a_{\mathrm{g}} Z \mathrm{IF}-62\right)_{0.5}$, and scanning electron microscopy images taken of a fragment of (c) (MIL-118) $0.5\left(a_{\mathrm{g}} \mathrm{ZIF}-62\right)_{0.5}$, and (d) (UL-MOF1) $0.5\left(a_{\mathrm{g}} \mathrm{ZIF}-62\right)_{0.5}$

Methane $\left(\mathrm{CH}_{4}\right)$ adsorption for $a_{\mathrm{g}} \mathrm{ZIF}-62$ was observed in this work at $0.21 \mathrm{mmol} \mathrm{g}^{-1}$ at $273 \mathrm{~K}$ (Fig. S19†), in agreement with the reported measurement of $0.18 \mathrm{mmol} \mathrm{g}^{-1}$ and representing a decrease from the reported value of $1.21 \mathrm{mmol} \mathrm{g}^{-1}$ in the crystalline ZIF-62. ${ }^{30}$ Hysteresis is observed in the $a_{\mathrm{g} Z I F-62}$ isotherms as a result of the diffusion limitations through the amorphous structure, increasing in magnitude with the kinetic diameter of the adsorbent, also consistent with prior work. ${ }^{31,32}$ This is especially evident in the propene isotherm, with the uptake amount appearing to diminish in the region 70-100 kPa. This is an artefact of slow diffusion kinetics. The recorded adsorption/desorption points are not at equilibrium and are imperfectly estimated in the higher-pressure region.

Remarkably, in addition to the reported selectivity towards propane $\left(\mathrm{C}_{3} \mathrm{H}_{8}\right)$ and propene $\left(\mathrm{C}_{3} \mathrm{H}_{6}\right)$ by $a_{\mathrm{g}} \mathrm{ZIF}-62$ by FrentzelBeyme et al., ${ }^{31}$ some selectivity towards ethene $\left(\mathrm{C}_{2} \mathrm{H}_{4}\right)$ over ethane $\left(\mathrm{C}_{2} \mathrm{H}_{6}\right)$ is observed here with uptakes of 0.46 and $0.29 \mathrm{mmol} \mathrm{g}^{-1}$, respectively (Fig. 4). Industrially, the separation

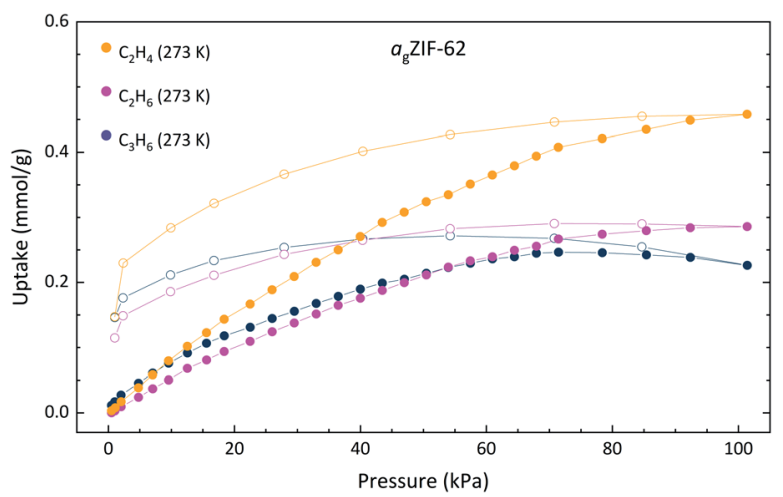

Fig. 4 Gas adsorption isotherms of $a_{g}$ ZIF-62. Solid and open circles of the same colour indicate the adsorption and desorption respectively.
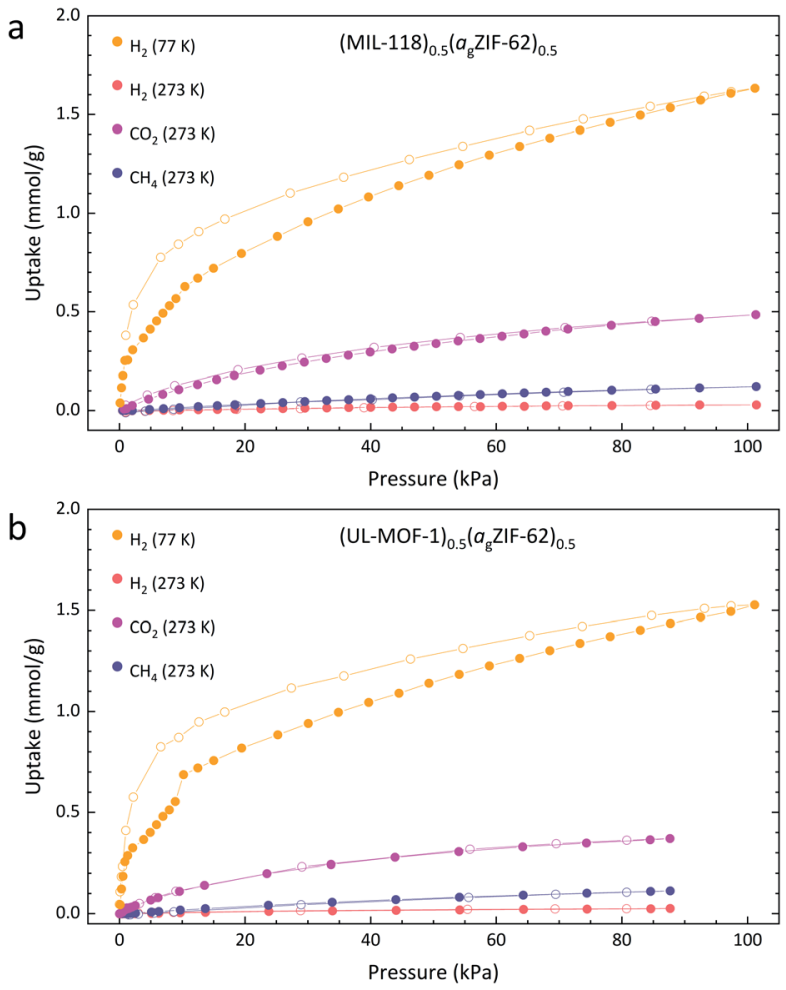

Fig. 5 Gas adsorption isotherms of samples of (a) (MIL-118) $)_{0.5}\left(a_{\mathrm{g}} \mathrm{ZIF}\right.$ $62)_{0.5}$ and (b) (UL-MOF-1 $)_{0.5}\left(a_{\mathrm{g}} \mathrm{ZIF}-62\right)_{0.5}$. Solid and open circles of the same colour indicate the adsorption and desorption respectively.

of small hydrocarbons is currently performed using cryogenic high-pressure distillation processes and accounts for a large portion of global energy expenditure. Membrane-based separation of these materials is reportedly tenfold less energyintensive, making development in this area both environmentally and economically desirable. ${ }^{33}$

To understand how incorporation within $a_{\mathrm{g}}$ ZIF-62 affects the gas sorption properties of the crystalline MOF, we compare the results for the pure crystalline material to that of the MOF CGC. Samples of MIL-118C and (MIL-118) $)_{0.5}\left(a_{\mathrm{g}} \text { ZIF-62 }\right)_{0.5}$ display identical trends in their adsorption isotherms of $\mathrm{H}_{2}, \mathrm{CH}_{4}$, and $\mathrm{CO}_{2}$, indicating no significant change in the chemical environment of MIL-118 upon inclusion in the MOF CGC (Fig. 5a and $\mathrm{S} 20 \dagger$ ). Since MIL-118C displays porosity to $\mathrm{H}_{2}$ at $77 \mathrm{~K}$, the negligible uptake of $\mathrm{H}_{2}$ at $273 \mathrm{~K}$ is ascribed to temperature effects. However, the generally poor uptake capacity of MIL$118 \mathrm{C}$ is consistent with a dense atomic arrangement, in accordance with the published crystallographic information. ${ }^{24}$

The adsorption of gases at $273 \mathrm{~K}$ by the $50 \mathrm{wt} \%$ composite material, (MIL-118) $)_{0.5}\left(a_{\mathrm{g} Z \mathrm{ZIF}-62}\right)_{0.5}$, is broadly comparable to a linear combination of the parent materials (Table 2). This, however, is not the case for $\mathrm{H}_{2}$ adsorption at $77 \mathrm{~K}$. Here, the recorded composite uptake is greater than either of its parent components and more than double the weighted average of the parent materials; this may suggest the presence of macroporous interfacial regions.

Identical experiments were performed on UL-MOF-1 and (UL-MOF-1 $)_{0.5}\left(a_{\mathrm{g}} \text { ZIF-62 }\right)_{0.5}$, and again, the generally poor 
Table 2 Predicted and experimentally measured gas uptake of MOF crystal-glass composites based on the combination of their parent materials. Experimental temperatures of $273 \mathrm{~K}$ unless otherwise stated

\begin{tabular}{lllll}
\hline & $\begin{array}{l}\text { Crystalline } \\
\text { MOF }(\mathrm{mmol}\end{array}$ & $\begin{array}{l}\text { Weighted } \\
\mathrm{g}_{\mathrm{g} Z \mathrm{ZIF}-62} \\
\left.\mathrm{~g}^{-1}\right)\end{array}$ & $\begin{array}{l}\text { Measured } \\
\text { MOF } \\
\text { Sample/gas } \\
\left(\mathrm{mmol} \mathrm{g}^{-1}\right)\end{array}$ & $\begin{array}{l}\text { CGC }(\mathrm{mmol} \\
\left.\mathrm{g}^{-1}\right)\end{array}$ \\
\hline $\begin{array}{l}\text { MIL-118 } \\
\text { Methane }\end{array}$ & 0.016 & 0.212 & 0.114 & 0.122 \\
$\begin{array}{l}\text { Carbon } \\
\text { dioxide }\end{array}$ & 0.152 & 0.947 & 0.550 & 0.485 \\
$\begin{array}{l}\text { Hydrogen } \\
\text { (77 K) }\end{array}$ & 0.440 & 1.051 & 0.746 & 1.632 \\
$\begin{array}{l}\text { UL-MOF-1 } \\
\text { Methane }\end{array}$ & 0.015 & 0.212 & & \\
$\begin{array}{l}\text { Carbon } \\
\text { dioxide }\end{array}$ & 0.051 & 0.947 & 0.113 & 0.113 \\
$\begin{array}{l}\text { Hydrogen } \\
\text { (77 K) }\end{array}$ & 0.320 & 1.051 & 0.499 & 0.370 \\
\hline
\end{tabular}

adsorption to UL-MOF-1 is consistent with a dense structure (Fig. 5b and S20†). The same thermal effects observed in the MIL-118 $\mathrm{H}_{2}$ isotherms at $77 \mathrm{~K}$ and $273 \mathrm{~K}$ were also observed for UL-MOF-1. The gas uptakes displayed by (UL-MOF-1 $)_{0.5}\left(a_{\mathrm{g}} \mathrm{ZIF}-\right.$ 62) 0.5 are broadly consistent with a linear combination of parent UL-MOF-1 and $a_{\mathrm{g}}$ ZIF-62 materials (Table 2). Interestingly, the 77 $\mathrm{K} \mathrm{H}_{2}$ sorption isotherm for (UL-MOF-1 $)_{0.5}\left(a_{\mathrm{g}} \mathrm{ZIF}-62\right)_{0.5}$ also exhibits a twofold increase in gas uptake over the weighted average of its parent materials.

The prediction of gas uptake through the weighted average of its components calculated here assume that the quantity of gas adsorbed in the MOF CGCs is due to the combined individual contributions from the two composited materials, where their adsorption is identical to the isolated components. It is important to note, however, that the hysteresis observed in the $\mathrm{CO}_{2}$ isotherms for both $a_{\mathrm{g}} \mathrm{ZIF}-62$ and the isolated crystalline MOFs is no longer present in the respective MOF CGCs. This suggests that the MOF CGC reaches equilibrium more rapidly than its isolated components, indicating that there may be new pathways for the gas to diffuse in the MOF CGC.

$\mathrm{A} \mathrm{CO}_{2}$ adsorption isotherm was also recorded at $273 \mathrm{~K}$ for the pure crystalline sample of MIL-53-np and is consistent with previously reported data $\left(2.25 \mathrm{mmol} \mathrm{g}{ }^{-1}\right.$ (recorded), and $2.13 \mathrm{mmol} \mathrm{g}^{-1}$ (reported) (273 K), Fig. S21†). ${ }^{17}$ As expected, MIL53-np displays a significantly higher uptake of $\mathrm{C}_{3} \mathrm{H}_{6}$ than $\mathrm{C}_{2} \mathrm{H}_{4}$, $\mathrm{C}_{2} \mathrm{H}_{6}$, or xenon (Xe), reaching $3.47 \mathrm{mmol} \mathrm{g}^{-1}(273 \mathrm{~K})$. The observation of two-step isotherms when using larger hydrocarbons is consistent with pore-opening behaviour where MIL-53$\mathrm{np}$ expands to the MIL-53-lp phase, as comprehensively illustrated in the literature. ${ }^{11}$

Consistent with our prior work, the MOF CGC exhibits appreciable porosity. However, due to fixation of the MIL-53-lp

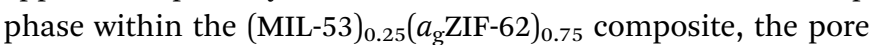
opening behaviour of pure phase MIL-53 is no longer observed, and all recorded isotherms of (MIL-53) $)_{0.25}\left(a_{\mathrm{g}} \text { ZIF-62 }\right)_{0.75}$ display

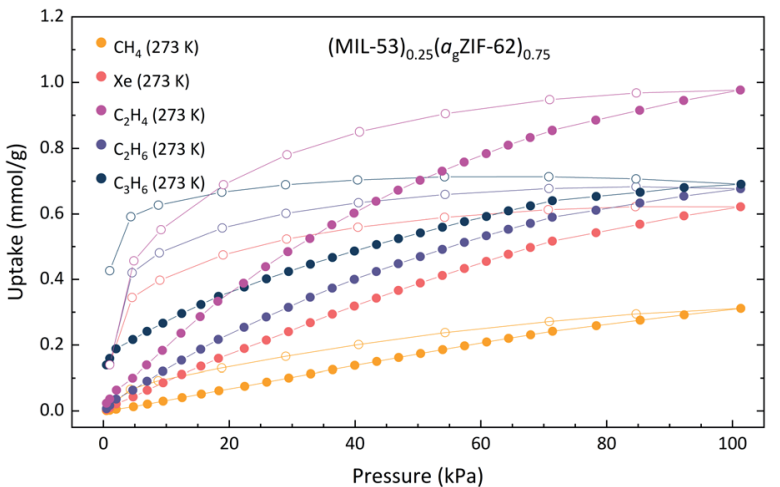

Fig. 6 Gas adsorption isotherms of (MIL-53) $)_{0.25}\left(a_{\mathrm{g}}\right.$ ZIF-62) 0.75 . Solid and open circles of the same colour indicate the adsorption and desorption respectively.

Langmuir-type behaviour, often with hysteresis in the desorption branch. The $\mathrm{CO}_{2}$ sorption of a sample of (MIL-53) $)_{0.25}\left(a_{\mathrm{g}} \mathrm{ZIF}-\right.$ 62) $)_{0.75}$ displayed similar $\mathrm{CO}_{2}$ uptake behaviour to that recorded previously $\left(1.33 \mathrm{mmol} \mathrm{g}^{-1}\right.$ (recorded), and $1.14 \mathrm{mmol} \mathrm{g}^{-1}$ (reported)). ${ }^{17}$ The sample of (MIL-53) $)_{0.25}\left(a_{\mathrm{g}} \mathrm{ZIF}-62\right)_{0.75}$ also displayed poor adsorption of both $\mathrm{N}_{2}$ and $\mathrm{CH}_{4} \quad(<0.13$ and $<0.36 \mathrm{mmol} \mathrm{g}^{-1}$ at $273 \mathrm{~K}$, respectively), since neither component of the CGC strongly adsorbs these gases (Fig. S22 $\dagger$ ).

Since this sample, unlike (MIL-118) $)_{0.5}\left(a_{\mathrm{g}} \mathrm{ZIF}-62\right)_{0.75}$ and (ULMOF-1 $)_{0.5}\left(a_{\mathrm{g} Z I F-62}\right)_{0.75}$, demonstrates a permeable crystalline component, further gas sorption experiments using larger gases were performed (Fig. 6). A considerable difference between the uptake of $\mathrm{C}_{2} \mathrm{H}_{4}$ and $\mathrm{C}_{2} \mathrm{H}_{6}$ is observed in a sample of (MIL53) $)_{0.25}\left(a_{\mathrm{g}} \mathrm{ZIF}-62\right)_{0.75}$, which is typical of the $a_{\mathrm{g} Z \mathrm{ZIF}-62}$ component but is not observed in MIL-53. This result evidences the contribution of the adsorption properties of $a_{\mathrm{g}} \mathrm{ZIF}-62$ to the overall composite characteristics.

Of the gases employed, the most striking result was that of $\mathrm{C}_{3} \mathrm{H}_{6}$, where the composite adsorbs far less than the combination of the parent materials. A weighted average $\mathrm{C}_{3} \mathrm{H}_{6}$ adsorption of MIL-53 $\left(3.47 \mathrm{mmol} \mathrm{g}^{-1}\right)$ and $a_{\mathrm{g}} \mathrm{ZIF}-62\left(0.23 \mathrm{mmol} \mathrm{g}^{-1}\right)$ for a $25 \mathrm{wt} \%$ MIL-53 mixture would be $1.04 \mathrm{mmol} \mathrm{g}^{-1}$, where an uptake of only $0.69 \mathrm{mmol} \mathrm{g}^{-1}$ is observed for the composite. However, the adsorption isotherm for $\mathrm{C}_{3} \mathrm{H}_{6}$ to (MIL$53)_{0.25}\left(a_{\mathrm{g}} \mathrm{ZIF}-62\right)_{0.75}$ shows an increase in uptake on desorption, strongly indicating that the system had not reached equilibrium. This is likely due to poor diffusion of $\mathrm{C}_{3} \mathrm{H}_{6}$ through the $a_{\mathrm{g} Z I F-62}$ matrix as a result of the comparatively large kinetic diameter of the gas. Though the MIL-53 component in the composite would be the dominant contributor to the gas uptake, adsorption to this component is greatly hindered whilst encapsulated within a matrix that is poorly permeable to the analyte gas.

\section{Conclusions}

Thermal analysis of a selection of crystalline MOFs revealed that two: UL-MOF-1, and MIL-118, are suitable for inclusion with a MOF glass $\left(a_{\text {gZIF-62 }}\right)$ matrix. Despite reported TGA evidence to the contrary, several other crystalline MOFs were observed to 
undergo partial or complete collapse at the processing temperatures required for composite formation. This highlights the necessity of detailed thermal characterisation and the avoidance of an over-reliance on constant-rate TGA experiments. ${ }^{19}$

It is clear from this research that to expand the scope of MOF CGCs to include frameworks with more diverse properties, new synthetic pathways must be explored. Two of such avenues may lie in (i) the utilisation of coordination polymers or MOFs with lower melting temperatures or (ii) exchanging the crystalline glass-forming MOF for a premade glass MOF. In doing so, the temperatures required for the fabrication of the MOF CGC may be reduced as the glass transition temperature $\left(T_{\mathrm{g}}\right)$ occurs at a lower temperature than the melting temperature $\left(T_{\mathrm{m}}\right)$ used here. $^{34-37}$

The adsorption behaviour of the resultant two new MOF CGCs is dominated by contributions from the $a_{\mathrm{g} Z \mathrm{ZIF}-62}$ matrix, which prevents the diffusion of molecules with a kinetic diameter larger than that of $\mathrm{C}_{3} \mathrm{H}_{6}$. The development of more permeable $a_{\mathrm{g} M O F s}$ may aid in the expansion of MOF CGC applicability. Alternatively, work on overcoming percolation thresholds in MOF CGCs would mean guest diffusion is primarily controlled by the crystalline MOF component. This would allow further control of interactions leading to multifunctional materials with the ability to act as both molecular sieves and separators.

\section{Experimental}

\section{Material synthesis}

CUmof-9. Ytterbium(III) chloride hexahydrate $(1.08 \mathrm{~g}, 2.79$ mmol) and water $(6.13 \mathrm{~mL})$ was added to a Teflon lined autoclave and stirred for 2 min. 2,6-Naphthalenedicarboxylic acid $(0.103 \mathrm{~g}, 0.476 \mathrm{mmol})$ and trimethylamine $(0.111 \mathrm{~mL})$ were added to the solution and the mixture was stirred for a further $5 \mathrm{~min}$. The suspension was then sealed and placed in a $145^{\circ} \mathrm{C}$ preheated oven for $4 \mathrm{~h}$. The reaction vessel was allowed to cool to room temperature (RT) and the product was isolated by filtration under vacuum and washed with ethanol $(30 \mathrm{~mL})$ before drying in the oven at $70{ }^{\circ} \mathrm{C}$ overnight.

DUT-6. Zinc nitrate tetrahydrate $(0.142 \mathrm{~g}, 0.543 \mathrm{mmol}), 2,6-$ naphthalenedicarboxylic acid $(0.017 \mathrm{~g}, 0.079 \mathrm{mmol})$, and benzene-1,3,5-tribenzoic acid $(0.054 \mathrm{~g}, 0.123 \mathrm{mmol})$ were dissolved in $N, N$-diethylformamide (DEF, $10 \mathrm{~mL}$ ). The mixture was sonicated for $5 \mathrm{~min}$ and heated to $100{ }^{\circ} \mathrm{C}$ for $24 \mathrm{~h}$ in a Pyrex tube. After cooling to RT the product was isolated by decanting the mother liquid and was washed with DEF. Yield: $49 \%$. The resulting solid was immersed in dichloromethane (DCM) for 2 days. During this time the DCM was replaced with fresh DCM three times. Elemental analysis calculated (\%) for $\mathrm{C}_{128} \mathrm{H}_{211} \mathrm{O}_{33.5} \mathrm{~N}_{16} \mathrm{Zn}_{4}$ : C 55.5, H 7.67, O 19.34, N 8.09, Zn 9.44; found: C $56.2 \pm 0.3, \mathrm{H} 7.66 \pm 0.07, \mathrm{O} 19.95 \pm 0.09, \mathrm{~N} 8.01 \pm 0.08$, Zn $9.22 \pm 0.05$.

DUT-8(Ni). Nickel nitrate hexahydrate $(0.407 \mathrm{~g}, 1.40 \mathrm{mmol})$ in $6 \mathrm{~mL}$ DMF, 2,6-naphthalenedicarboxylic acid $(0.303 \mathrm{~g}, 1.40$ $\mathrm{mmol}$ ) in $15 \mathrm{~mL}$ DMF and 1,4-diazabicyclo[2.2.2]octane $(0.100 \mathrm{~g}, 0.89 \mathrm{mmol})$ in $9 \mathrm{~mL}$ methanol $(\mathrm{MeOH})$ were mixed.
Subsequently the mixture was transferred into a Teflon vessel $(50 \mathrm{~mL})$ and heated in an autoclave to $120^{\circ} \mathrm{C}$ at a heating rate of $4{ }^{\circ} \mathrm{C} \mathrm{min}^{-1}$ and held at that temperature for $48 \mathrm{~h}$. After cooling to RT over $3 \mathrm{~h}$, the sample was washed three times, first with

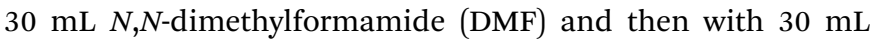
ethanol and finally with $30 \mathrm{~mL}$ DCM. Afterwards, a washing step with $150 \mathrm{~mL}$ of DCM was continued for 3 days. The resulting solid was filtered in an argon flow and activated under dynamic vacuum at $393 \mathrm{~K}$ for $4 \mathrm{~h}$.

MIL-53. Aluminum nitrate nonahydrate $\left(26 \mathrm{~g}, 6.93 \times 10^{-2}\right.$ $\mathrm{mol})$ and terephthalic acid $\left(5.76 \mathrm{~g}, 4.96 \times 10^{-2} \mathrm{~mol}\right)$ were dissolved in water $(100 \mathrm{~mL})$ and placed into a Teflon-lined autoclave, and then placed in an oven at $220{ }^{\circ} \mathrm{C}$ for $72 \mathrm{~h}$. The resulting powder was washed with deionised water $(3 \times 30 \mathrm{~mL})$ and dried in a vacuum oven at $150{ }^{\circ} \mathrm{C}$ for $24 \mathrm{~h}$. MIL-53 was activated by heating at $330{ }^{\circ} \mathrm{C}$ for $72 \mathrm{~h}$, and then to $450{ }^{\circ} \mathrm{C}$ for 6 min before cooling to RT.

MIL-68. Aluminum nitrate nonahydrate $(1.4 \mathrm{~g}, 6.57 \mathrm{mmol})$, benzene-1,4-dicarboxylic acid ( $0.6 \mathrm{~g}, 3.61 \mathrm{mmol})$, and tetrahydrofuran (THF, $16 \mathrm{~mL}$ ) were added to a $50 \mathrm{~mL}$ round bottom flask and refluxed for 3 days at $70{ }^{\circ} \mathrm{C}$. The resultant white powder was washed with THF $(3 \times 15 \mathrm{~mL})$ and dried at RT overnight. To remove excess linker from the pores, the product was activated by heating to $300{ }^{\circ} \mathrm{C}$ at $1{ }^{\circ} \mathrm{C} \mathrm{min}-1$ and held for $8 \mathrm{~h}$.

MIL-118. Aluminum nitrate nonahydrate $(150 \mathrm{mg}, 7.04 \times$ $10^{-4} \mathrm{~mol}$ ) and benzene-1,2,4,5-tetracarboxylic acid (50 mg, 1.97 $\times 10^{-4} \mathrm{~mol}$ ) were added to a Teflon lined autoclave before adding water $(5 \mathrm{~mL})$. The autoclave was sealed and placed into a $210{ }^{\circ} \mathrm{C}$ preheated oven for $24 \mathrm{~h}$. The product of this was isolated by replacing the liquid with water $(20 \mathrm{~mL})$ and centrifuging $(2500 \mathrm{rpm}, 10 \mathrm{~min})$ twice. The resultant white powder was placed in a $70^{\circ} \mathrm{C}$ preheated oven overnight.

MIL-120. Aluminium nitrate nonahydrate $(1.44 \mathrm{~g}, 6.76$ $\mathrm{mmol})$, 1,2,4,5-benzenetetracarboxylic acid $(0.225 \mathrm{~g}, 0.885$ $\mathrm{mmol})$, sodium hydroxide $(4 \mathrm{M}, 1.53 \mathrm{~mL})$, and water $(9 \mathrm{~mL})$ were added to a Teflon lined autoclave and placed in a $210^{\circ} \mathrm{C}$ preheated oven and held for $24 \mathrm{~h}$. The resulting white powder was filtered and washed with water $(40 \mathrm{~mL})$ before being transferred to a $100 \mathrm{~mL}$ round-bottom flask with water $(60 \mathrm{~mL})$, and refluxed at $100{ }^{\circ} \mathrm{C}$ for $10 \mathrm{~h}$. The product was centrifuged (2500 rpm, $15 \mathrm{~min}$ ) and dried in the over at $70{ }^{\circ} \mathrm{C}$ overnight. Further to the reported method, MIL-120 was heated to $280^{\circ} \mathrm{C}$ to produce a white powder with a PXRD pattern matching the predicted pattern.

MIL-126(Sc). Scandium nitrate hydrate ( $85 \mathrm{mg}, 0.368 \mathrm{mmol}$ ), biphenyl-4,4'-dicarboxylic acid ( $68 \mathrm{mg}, 0.281 \mathrm{mmol})$, DMF (6.25 $\mathrm{mL})$, conc. hydrochloric acid $(37 \%, 25 \mu \mathrm{L})$ were added to a $25 \mathrm{~mL}$ screw-top jar and sonicated until dissolution $(\sim 15$ min). The clear solution was placed into a $120{ }^{\circ} \mathrm{C}$ preheated oven for $24 \mathrm{~h}$. The product was transferred to a centrifuge tube and centrifuged ( $2500 \mathrm{rpm}, 15 \mathrm{~min}$ ) to collect a white powder. This powder was stood in DMF $(10 \mathrm{~mL})$ overnight and centrifuged again ( $2500 \mathrm{rpm}, 10 \mathrm{~min}$ ) and acetone exchanged three times over three days before collecting the product by centrifuging ( $2500 \mathrm{rpm}, 5 \mathrm{~min}$ ), decanting the liquid and drying in a $60{ }^{\circ} \mathrm{C}$ preheated oven overnight. 
ULMOF-1. Lithium nitrate $\left(0.345 \mathrm{~g}, 5.00 \times 10^{-3} \mathrm{~mol}\right)$, naphthalene-2,6-dicarboxylic acid (0.565 g, $\left.2.61 \times 10^{-3} \mathrm{~mol}\right)$, ammonium fluoride (38 mg), and DMF (15 mL) were added to Teflon lined autoclave and placed in a $180{ }^{\circ} \mathrm{C}$ preheated oven and held for 5 days. Upon cooling, the reaction mixture was transferred to a centrifuge tube and the liquid was replaced with ethanol $(20 \mathrm{~mL})$. The sample was stirred for $5 \mathrm{~min}$ before centrifuging (3000 rpm, $5 \mathrm{~min}$ ) to collect a white powder which was dried in an oven at $60{ }^{\circ} \mathrm{C}$ overnight.

ZIF-62. Zinc nitrate hexahydrate $\left(1.65 \mathrm{~g}, 5.54 \times 10^{-3} \mathrm{~mol}\right)$ and imidazole $(8.91 \mathrm{~g}, 0.13 \mathrm{~mol})$ were added to a $200 \mathrm{~mL}$ screwtop jar, dissolved in DMF (75 mL) and stirred for $1 \mathrm{~h}$. Once complete dissolution was achieved, benzimidazole $(1.55 \mathrm{~g}, 1.31$ $\times 10^{-2} \mathrm{~mol}$ ) was added and heated to $130{ }^{\circ} \mathrm{C}$ for $48 \mathrm{~h}$. The product was allowed to cool to RT and crystals were separated by vacuum-assisted filtration and washed with $\mathrm{DMF}(40 \mathrm{~mL})$ and DCM (40 mL) before being dried in an oven at $60^{\circ} \mathrm{C}$ overnight.

$\boldsymbol{a}_{\mathrm{g}}$ ZIF-62. $150 \mathrm{mg}$ of ZIF-62 was heated to $450{ }^{\circ} \mathrm{C}$ in a furnace at a rate of $10{ }^{\circ} \mathrm{C} \mathrm{min}^{-1}$ under an argon (Ar) atmosphere, and held for $15 \mathrm{~min}$ before being allowed to cool to RT.

MOF CGC materials. ZIF-62 and the corresponding crystalline material were ball-milled together using a Retsch MM400 instrument, in appropriate $\mathrm{wt} \%$ ratios using a $7 \mathrm{~mm}$-diameter stainless steel ball for $15 \mathrm{~min}$, at a frequency of $30 \mathrm{~Hz}$. The mixed powder was pressed in a $13 \mathrm{~mm}$-diameter dye at $0.74 \mathrm{GPa}$ for $1 \mathrm{~min}$. The pellet was then clamped between glass slides, heated to $450{ }^{\circ} \mathrm{C}$ in a tube furnace at a rate of $20^{\circ} \mathrm{C} \mathrm{min}^{-1}$ under an $\mathrm{Ar}$ atmosphere, and held for $15 \mathrm{~min}$ before being allowed to cool to RT.

\section{Characterisation}

Powder X-ray diffraction. Data were collected on ground samples of the composite materials with a Bruker D8 Advance powder diffractometer using $\mathrm{Cu} \mathrm{K} \alpha$ radiation $(\lambda=1.5418 \AA)$ and a LynxEye position-sensitive detector in Bragg-Brentano $(\theta-\theta)$ parafocusing geometry at RT. Diffraction patterns were recorded at $2 \theta$ values of $5-40^{\circ}$ with a time/step of $0.75 \mathrm{~s}$ over 1724 steps through a $0.012 \mathrm{~mm}$ Ni filter.

Scanning electron microscopy. SEM was performed using a Thermo ScientifictM Phenom ProX scanning electron microscope. Powder and monolithic samples were prepared for SEM by securing to aluminum SEM pin stubs using carbon tape. Samples were coated in gold using an Emtech K575 sputter coater.

Thermogravimetric analysis. Thermogravimetric analysis was performed using a TA Q500 TGA. All scans were performed at $10{ }^{\circ} \mathrm{C} \mathrm{min}^{-1}$ with a nitrogen protective gas and allowed to cool to RT with air.

Gas sorption. Samples were degassed overnight at the specified temperature for $12 \mathrm{~h}$ on before transferring to the analysis port of a Quantachrome iQ2 instrument. Sample weight was measured post-degas activation. Sample temperature was accurately equilibrated at $273 \mathrm{~K}$ and $293 \mathrm{~K}$ with a temperaturecontrolled water bath and at $77 \mathrm{~K}$ with liquid $\mathrm{N}_{2}$. Gas adsorption measurements were performed using ultra-high purity (99.99\%) gases.

\section{Author contributions}

C. W. A. and T. D. B. designed the project with assistance from S. G. T. Materials were synthesised by C. W. A. with assistance from Y. Z. ( $a_{\mathrm{g}}$ ZIF-62), and S. K. (DUT-6 and DUT-8). C. W. A. recorded PXRD and TGA data and performed Pawley refinements. T. J. F. S. and C. W. A. prepared samples and recorded SEM images. Gas sorption experiments were performed by $\mathrm{L}$. K. M., S. G. T., C. W. A., and Y. Z. The manuscript was written by all authors.

\section{Conflicts of interest}

There are no conflicts to declare.

\section{Acknowledgements}

T. D. B. thanks the Royal Society for both a university research fellowship (UF150021) and a research grant (RSG $\backslash$ R1 $\backslash 180395)$. T. D. B. and L. N. M. thank the Leverhulme Trust for a Philip Leverhulme Prize (2019). C. W. A. thanks the Royal Society for a PhD studentship (RG160498) and the Commonwealth Scientific and Industrial Research Council for additional support (C2017/3108). T. J. F. S. thanks the EPSRC (EP/1937468) for a PhD studentship. S. K. acknowledges funding by DFG (FOR2433). S. G. T. thanks the Royal Society of New Zealand for the catalyst seeding grant (18-MAU-022-CSG).

\section{Notes and references}

1 H. Furukawa, K. E. Cordova, M. O'Keeffe and O. M. Yaghi, Science, 2013, 341, 120444.

2 P. Z. Moghadam, A. Li, X. W. Liu, R. Bueno-Perez, S. D. Wang, S. B. Wiggin, P. A. Wood and D. Fairen-Jimenez, Chem. Sci., 2020, 11, 8373-8387.

3 I. M. Hönicke, I. Senkovska, V. Bon, I. A. Baburin, N. Bönisch, S. Raschke, J. D. Evans and S. Kaskel, Angew. Chem., Int. Ed., 2018, 57, 13780-13783.

4 O. K. Farha, I. Eryazici, N. C. Jeong, B. G. Hauser, C. E. Wilmer, A. A. Sarjeant, R. Q. Snurr, S. T. Nguyen, A. Ö. Yazaydin and J. T. Hupp, J. Am. Chem. Soc., 2012, 134, 15016-15021.

5 T. Islamoglu, Z. Chen, M. C. Wasson, C. T. Buru, K. O. Kirlikovali, U. Afrin, M. R. Mian and O. K. Farha, Chem. Rev., 2020, 120, 8130-8160.

6 I. M. Hönicke, I. Senkovska, V. Bon, I. A. Baburin, N. Bönisch, S. Raschke, J. D. Evans and S. Kaskel, Angew. Chem., Int. Ed., 2018, 57, 13780-13783.

7 H. Kim, S. Yang, S. R. Rao, S. Narayanan, E. A. Kapustin, H. Furukawa, A. S. Umans, O. M. Yaghi and E. N. Wang, Science, 2017, 356, 430-434.

8 F. X. Coudert, Chem. Mater., 2015, 27, 1905-1916.

9 J. Hajek, C. Caratelli, R. Demuynck, L. Vanduyfhuys, M. Waroquier and V. Van Speybroeck, Chem. Sci., 2018, 9, 2723-2732.

10 A. Schneemann, V. Bon, I. Schwedler, I. Senkovska, S. Kaskel and R. A. Fischer, Chem. Soc. Rev., 2014, 43, 6062-6096. 
11 T. Loiseau, C. Serre, C. Huguenard, G. Fink, F. Taulelle, M. Henry, T. Bataille and G. Férey, Chem.-Eur. J., 2004, 10, 1373-1382.

12 E. J. Carrington, C. A. McAnally, A. J. Fletcher, S. P. Thompson, M. Warren and L. Brammer, Nat. Chem., 2017, 9, 882-889.

13 T. D. Bennett, J.-C. Tan, Y. Yue, E. Baxter, C. Ducati, N. J. Terrill, H. H.-M. Yeung, Z. Zhou, W. Chen, S. Henke, A. K. Cheetham and G. N. Greaves, Nat. Commun., 2015, 6, 8079.

14 R. Banerjee, A. Phan, B. Wang, C. Knobler, H. Furukawa, M. O'Keefe and O. M. Yaghi, Science, 2008, 319, 939-944.

15 T. D. Bennett, Y. Yue, P. Li, A. Qiao, H. Tao, N. G. Greaves, T. Richards, G. I. Lampronti, S. A. T. Redfern, F. Blanc, O. K. Farha, J. T. Hupp, A. K. Cheetham and D. A. Keen, J. Am. Chem. Soc., 2016, 138, 3484-3492.

16 J. Hou, C. W. Ashling, S. M. Collins, A. Krajnc, C. Zhou, L. Longley, D. N. Johnstone, P. A. Chater, S. Li, M.-V. Coulet, P. L. Llewellyn, F.-X. Coudert, D. A. Keen, P. A. Midgley, G. Mali, V. Chen and T. D. Bennett, Nat. Commun., 2019, 10, 2580.

17 C. W. Ashling, D. N. Johnstone, R. N. Widmer, J. Hou, S. M. Collins, A. F. Sapnik, A. M. Bumstead, P. A. Midgley, P. A. Chater, D. A. Keen and T. D. Bennett, J. Am. Chem. Soc., 2019, 141, 15641-15648.

18 S. Li, S. Yu, S. M. Collins, D. N. Johnstone, C. W. Ashling, A. F. Sapnik, P. A. Chater, D. S. Keeble, L. N. McHugh, P. A. Midgley, D. A. Keen and T. D. Bennett, Chem. Sci., 2020, 11, 9910-9918.

19 C. Healy, K. M. Patil, B. H. Wilson, L. Hermanspahn, N. C. Harvey-Reid, B. I. Howard, C. Kleinjan, J. Kolien, F. Payet, S. G. Telfer, P. E. Kruger and T. D. Bennett, Coord. Chem. Rev., 2020, 419, 213388.

20 F. A. A. Paz and J. Klinowski, Chem. Commun., 2003, 14841485.

21 N. Klein, I. Senkovska, K. Gedrich, U. Stoeck, A. Henschel, U. Mueller and S. Kaskel, Angew. Chem., Int. Ed., 2009, 48, 9954-9957.

22 N. Klein, C. Herzog, M. Sabo, I. Senkovska, J. Getzschmann, S. Paasch, M. R. Lohe, E. Brunner and S. Kaskel, Phys. Chem. Chem. Phys., 2010, 12, 11778-11784.

23 B. Seoane, V. Sebastián, C. Téllez and J. Coronas, CrystEngComm, 2013, 15, 9483-9490.
24 C. Volkringer, T. Loiseau, N. Guillou, M. Haouas, F. Taulelle, N. Audebrand, I. Margiolaki, D. Popov, M. Burghammer and C. Riekel, Cryst. Growth Des., 2009, 9, 2927-2936.

25 C. Volkringer, T. Loiseau, M. Haouas, F. Taulelle, D. Popov, M. Burghammer, C. Riekel, C. Zlotea, F. Cuevas, M. Latroche, D. Phanon, C. Knöfelv, P. L. Llewellyn and G. Férey, Chem. Mater., 2009, 21, 5783-5791.

26 R. J. Marshall, C. T. Lennon, A. Tao, H. M. Senn, C. Wilson, D. Fairen-Jimenez and R. S. Forgan, J. Mater. Chem. A, 2018, 6, 1181-1187.

27 D. Banerjee, S. J. Kim and J. B. Parise, Cryst. Growth Des., 2009, 9, 2500-2503.

28 R. N. Widmer, G. I. Lampronti, S. Anzellini, R. Gaillac, S. Farsang, C. Zhou, A. M. Belenguer, C. W. Wilson, H. Palmer, A. K. Kleppe, M. T. Wharmby, X. Yu, S. M. Cohen, S. G. Telfer, S. A. T. Redfern, F. X. Coudert, S. G. MacLeod and T. D. Bennett, Nat. Mater., 2019, 18, 370-376.

29 C. Zhou, L. Longley, A. Krajnc, G. J. Smales, A. Qiao, I. Erucar, C. M. Doherty, A. W. Thornton, A. J. Hill, C. W. Ashling, O. T. Qazvini, S. J. Lee, P. A. Chater, N. J. Terrill, A. J. Smith, Y. Yue, G. Mali, D. A. Keen, S. G. Telfer and T. D. Bennett, Nat. Commun., 2018, 9, 1-9.

30 L. Longley, S. M. Collins, S. Li, G. J. Smales, I. Erucar, A. Qiao, J. Hou, C. M. Doherty, A. W. Thornton, A. J. Hill, X. Yu, N. J. Terrill, A. J. Smith, S. M. Cohen, P. A. Midgley, D. A. Keen, S. G. Telfer and T. D. Bennett, Chem. Sci., 2019, 10, 3592-3601.

31 L. Frentzel-Beyme, M. Kloß, P. Kolodzeiski, R. Pallach and S. Henke, J. Am. Chem. Soc., 2019, 141, 12362-12371.

32 L. Frentzel-Beyme, M. Kloß, R. Pallach, S. Salamon, H. Moldenhauer, J. Landers, H. Wende, J. Debus and S. Henke, J. Mater. Chem. A, 2019, 7, 985-990.

33 D. S. Sholl and R. P. Lively, Nature, 2016, 532, 435-437.

34 S. S. Nagarkar, H. Kurasho, N. T. Duong, Y. Nishiyama, S. Kitagawa and S. Horike, Chem. Commun., 2019, 55, 5455-5458.

35 A. M. Bumstead, M. F. Thorne and T. D. Bennett, Faraday Discuss., 2021, 225, 210-225.

36 C. Das, T. Ogawa and S. Horike, Chem. Commun., 2020, 56, 8980-8983.

37 B. K. Shaw, A. R. Hughes, M. Ducamp, D. A. Keen, F.-X. Coudert, F. Blanc and T. D. Bennett, ChemRxiv, 2020, DOI: 10.26434/chemrxiv.11956599.v1. 